\title{
Factors of Success in Implementation of Enterprise Resource Planning Systems
}

\author{
REZARTA SHKURTI (PERRI) \\ Professor, Department of Accounting \\ University of Tirana, Tirana \\ Orcid ID: 0000-0002-2126-2339 \\ ALBANIA \\ ELFRIDA MANOKU \\ Professor, Department of Marketing \\ University of Tirana, Tirana
}

\begin{abstract}
ALBANIA
Abstract: - Implementing complex and yet sound and effective accounting information systems known as enterprise resource planning systems, is an enormous project for the firms that want to streamline their information flow and increase their value. As the effects of these systems on the performance of the entities are both financial and non-financial, their success is of crucial importance. This study is an exploratory factorial analysis to identify the factors of successful implementation of ERP systems in the medium and big companies in Albania. We use in depth surveys and interviews with firms that have implemented enterprise resource planning systems and include twenty initial variables in the survey. Later these variables are combined in three factors that have the biggest impact on the success rate of ERP implementation: the overall quality and end-user satisfaction with the ERP system; the cost-benefit ratio of the ERP and the support from the ERP provider and ERP implementing consultant. This study contributes not only theoretically to the empirical literature, but also practically because it helps businesses of the region that are considering implementing ERPs in the future to pay attention to the most critical factors of success with ERPs.
\end{abstract}

Key-Words: - Enterprise resource planning, ERP successful implementation, Factorial analysis.

Received: February 15, 2021. Revised: June 14, 2021. Accepted: July 2, 2021. Published: July 7, 2021

\section{Introduction}

The use of Information and Communication Technology tools in finance and accounting has brought many advantages in improving the quality and timeliness of the information flow within entities. A distinguishable mainstream has been the adoption and implementation of computerized accounting information systems. Utilizing and relying on such systems has become a necessity for processing and reporting information for both internal and external users of information. Successfully implementing and running efficient computerized information systems that facilitate the flow of information is a critical factor for success for companies. Data communication and processing should be streamlined and coordinated among many departments and sectors. As reported in an innovative study as early as 1992: "in the information age, the ability of the companies to exploit intangible assets such as data and information has become far more decisive in their success than the ability to manage physical or financial assets" [1].

Recently, the focus has been on the accuracy and timeliness of information, the use of cloud solutions and extensive reporting business language. The data processing is not considered a supportive role anymore but rather a major operation area of an economic entity, engaging many employees and requiring extensive financial and human resources [2, $3,4]$.

Enterprise Resource Planning systems (ERP) represent comprehensive and integrated solutions for 
managing the information in such a way that help companies achieve their tactical and strategic goals. Often, they are also addressed to as: software packages, enterprise systems, wide-enterprise systems, enterprise business systems, integrated software's, and enterprise application systems [5, 6, 7].

The definition of ERPs has evolved over time as they have become more complex and sophisticated, undertaking more and more functionalities within an entity. Some early definitions of ERP are: "a unique way to integrate all the functions by creating a single unified system, rather than separated applications", "software packages that connect and manage the information flow within and between complex organizations, allowing managers to take decisions based on information that truly reflects the current state of the business", "support systems that gather in a single database the data needed for various business functions such as manufacture, finance and supply chain", "first approach that combines the concepts of integrated business management with the information technology" [8 - 11]. The biggest advantage of an ERP system is the change it brings in the organization and culture of the entities and its focus on reengineering their business processes [12].

Nevertheless, implementing ERPs does not come without its challenges. According to a report by Deloitte Canada ${ }^{1} 55 \%$ to $75 \%$ of the ERP projects fail sooner or later for different reasons. Studies have also reported that the performance of many companies has deteriorated during the first immediate phase after the ERP implementation [13].

Considering the recent trend we observe in the implementation of ERP systems by the big companies in Albania, it is important to study the success (or failure) of these projects and the possible impact on the performance of the entities. Thus, this study may contribute to the stream of similar research of IT solutions in accounting and finance and it may also have practical implications for companies that may decide to implement ERPs in the future.

The structure of this paper is as follows: in the following section we present a brief literature overview on the impact of ERP systems on business performance and factors leading toward ERP success. Next, we present the methodology of the study, the

\footnotetext{
${ }^{1}$ https://www2.deloitte.com/content/dam/Deloitte/mx/Documents/humancapital/01_ERP_Top10_Challenges.pdf
}

main research questions, the methods, the sample, and the data analysis. We conclude the paper by summarizing the main findings and conclusions of the study, as well as its contributions and limitations.

\section{Literature Review}

Studies focusing on the ERP systems and how they became one of the largest investment trends in Information Technology by many companies, are published since late 90s [14]. By the 2000s, it was evident that ERPs were considered a major force to drive the transformation and business reengineering processes of many entities in a various array of business sectors [10]. The extensive investments in financial and non-financial resources required by any ERP project, soon brought under a careful attention, the analysis of costs and benefits from these projects. Many studies focused on investigating the impact that such big and sophisticated systems had on the performance indicators of the entities [15].

At the beginning, the companies adopting ERP solutions were expecting enhancement in the efficiency of operations and information management, and therefore, improvement of financial performance indicators compared to the non-adopting companies, [8]. Theoretical literature suggested that strategic investments in IT in general and ERPs in particular, give to the entities the opportunity to materialize tangible and intangible benefits, and help them to maintain the necessary operational efficiency for a long time [16]. The expectations from ERPs were high, but the first studies from this period report mixed results. A comparative study [17] found that while ERP adopters demonstrated no difference in financial performance after ERP implementation, the performance of non-adopter's had deteriorated during the same period. Another early study in 2004, reported that at least two years are required for the ERP adopters to begin experiencing positive differences in the financial performance compared to non-adopters [13].

Many studies reported deterioration of the profits and overall productivity of companies, immediately after they had implemented the ERP systems [8; 18; $19 ; 20]$. There may be many reasons for that, such as: a long-time learning curve of ERPs themselves; unexpected issues with the integration of the new systems with existing technology; internal conflict in organizations and resistance to change; changes in top 
level management during the implementation project; and technical issues during and after the implementation [21 - 24]. As early as 1999, one study [25] anticipated that organizations relying on ERP systems may experience a temporary deterioration of the performance and the productivity, because their activities would become more complex and the organization itself would require some time to adapt to these changes.

Deciding whether an ERP implementation project has in fact been successful or not, and then measuring its success appears to be a quite researched stream in the literature. What exactly is meant by "a successful implementation of an ERP project" varies among different authors. One study focusing on critical issues in ERP implementation, [26] defined the success as: "the completion and the implementation of the ERP both, on time and on budget". They report that the most common issues that hinder an ERP project from being successfully implemented are the selection of ERP vendor, the project manager, and the implementation partners; the project team; project planning, training, infrastructure development, and on-going project management; and the quality assurance.

From the ERP user's perspective, the success is defined as "the ERP simplicity, user-friendliness, and the improvements it brings in the daily tasks of employees". It was anticipated that ERP systems would add value to the organization through integration, optimization, and information [8]. Later findings report that the firms that had implemented ERP systems, were able to create more value in the long run [27]. Very recently, the success of ERPs is also defined as the impact it brings on the performance measurement of the employees, providing evidence that ERP not only improves the financial performance indicators, but also the nonfinancial performance as well [28].

Other more recent studies are focusing more on the effects that ERP systems might have on the firms' risks or the firms' organization, the undesired consequences arising from an ERP implementation, or the specific features of ERP implementation in various industries [29-32].

The most common methodology used in the literature to identify the factors of ERP success, is the explorative factorial analysis [33, 34]. From the general literature review we find that ERP systems represent a risky initiative for firms when considering factors such as their complexity, the size of required investments in hardware, software and human resources, the impact on the business value, overall company culture and procedures the implementation. Hence, carefully researching the success factors may help companies and ERP consultants to achieve better results in the future.

\section{Methodology}

Throughout this study we focus on two main research questions: (1) what are the factors that affect the success of ERP implementation; and (2) In what extent does the use of ERP affects the performance of businesses in Albania?

The first research question focuses on identifying those factors that may impact the success (or failure) of the ERP project. To answer this question, we identify various variables that measure the ERP success and then, using the explorative factorial analysis, we combine these variables in factors that seem to have had the greatest impact ${ }^{2}$.

Once we identify the most important factors that impact the ERP's success, through the second research question, we attempt to measure the degree of this impact. We use in-depth surveys in entities that have implemented ERP solutions during the last five years.

To develop the sample for this study as a first step we identify the medium and big firms that have recently (within the last five years) implemented ERP solutions, either recognized international ERPs from SAP, ORACLE and NAV, or ERPs offered by local vendors, such as AlphaWeb offered by IMB, a major Albanian company. We sent out 200 questionnaires via electronic means, using mainly the email addresses found under the contact section in the web pages of the firms, and two weeks after the initial email, we followed up with a second reminder email. When possible, multiple emails were sent to multiple contact electronic addresses to ensure that at least one representative per each entity would complete the survey. At a later step we excluded from the sample the redundant questionaries completed by the same firm.

We received 63 completed questionnaires, but after a close inspection we noticed that only 55 were complete and appropriate to be included for further

\footnotetext{
${ }^{2}$ Factorial analysis is used to combine many various variables into few factors that can be interpreted and analyzed easier [34]
} 
analysis in the step of data analysis. The response rate of the survey was $28 \%$ and as it was delivered and completed online, we consider this sample to be an acceptable representation of the population ${ }^{3}$. The survey was administered online through Google Forms tool and was piloted among colleagues to be improved before its final submission to the interested subjects. The data was processed through a statistical package (SPSS program).

The questionnaire was organized in three sections and had 30 questions in total. The first section focused on general information about the respondent (size of the firm, industry, invested capital origin, implemented ERP origin). The next section of the survey focused on the first research question and how the performance of the organization had changed after the ERP implementation. In this part of the questionnaire, we included questions on 20 initial variables that, based on findings from previous literature we expected to affect the firms' performance after ERP implementation. These 20 variables were later aggregated into three factors based on the responses received from the respondents.

The last section of the questionnaire was related to the second research question and focused on measuring the magnitude of the impact of each of the identified factors on the firms' performance. All the questions in the survey vary from close question to open questions, and questions organized in Likert scale (from 1 to 5 ).

\section{Data Analysis}

The questionnaire is organized in three distinct sections where the first one focuses on general information. In table 1 we present the descriptive statistics of the sample in this study, in terms of size (size categorization is based on criteria according to Albanian law), industrial sector, capital origin (whether domestic or foreign capital) and origin of the ERP implemented, whether it is from a foreign ERP vendor, or from a local vendor in Albania. We also include questions on specific data concerning the ERP such as the module(s) used more often and the ERP implementation time.

\footnotetext{
${ }^{3}$ Visser, et al, (1996) reports that on line surveys with lower return rate responses (at about $20 \%$ ) yield more accurate results than those with higher return rate (at about $60-70 \%$ ).
}

We see that although most of the firms in our sample operate in Albania, they are foreign capital companies and most of them use ERP from foreign vendors. This feature of the sample closely reflects the distribution of overall population of medium and big companies in our country, most of them are foreign companies. This is important to this study because the big companies are those that usually implement and use ERPs. Regarding the longevity of ERP software use in an entity we can see that most of them ( $75 \%$ of the entities) have been using the ERP systems for more than three years ${ }^{4}$.

The next set of questions in the survey tries to identify the features of the ERPs that are attractive to the businesses had decided to implement an ERP solution. We can see that most of the respondents are oriented toward the selection of an ERP which is flexible and adaptive to changing business environments not only during the implementation, but especially during later maintenance phase. Other important factors that serve as criteria to choose one ERP over another are the functionality of the solution and its simplicity for the end user, as well as the total costs of its implementation.

Next, we focus on measuring the perceived results of the ERP project, by asking the respondents to categorize the ERP project as successful, not successful or challenging. We offered three options for them to choose only one: "successful implementation" (if the project is completed on-time and on-budget, with all features and functions as initially specified)' "challenging" (if the project is completed and operational but over-budget, beyond deadline, and offers fewer features and functions than originally specified); and "failed" (if the project is simply canceled at some point during the development cycle). $65 \%$ of the respondents perceive the ERP project as successful, whereas $35 \%$ of them regard it as a challenging project. None of the respondents reports a failed implementation project.

\footnotetext{
${ }^{4}$ The 3 years limit was set because during literature review, researchers refer that the positive effect of ERP use are experienced in a period of approximately 3 years after implementation.
} 
Table 1. Sample descriptive statistics, $n=55$ total observations

\begin{tabular}{|c|c|c|c|}
\hline Measure & Category & $\underline{\text { Number }}$ & Percentage (\%) \\
\hline \multirow[t]{3}{*}{ Size } & Medium firms & 12 & $21.8 \%$ \\
\hline & Big companies & 43 & $78.2 \%$ \\
\hline & $\underline{\underline{T} \text { Total }}$ & $\underline{\underline{55}}$ & $\underline{100.0 \%}$ \\
\hline \multirow[t]{6}{*}{ Industrial sector } & Construction\&Manufacturing & 8 & $14.6 \%$ \\
\hline & Distribution \& Retail & 15 & $27.2 \%$ \\
\hline & Services & 16 & $29.1 \%$ \\
\hline & Financial sector & 9 & $16.3 \%$ \\
\hline & Other & 7 & $12.7 \%$ \\
\hline & $\underline{\underline{\text { Total }}}$ & $\underline{\underline{55}}$ & $\underline{100.0 \%}$ \\
\hline \multirow[t]{3}{*}{ Capital origin } & Domestic Company & 13 & $23.6 \%$ \\
\hline & Foreign Company & 42 & $76.3 \%$ \\
\hline & $\underline{\underline{\text { Total }}}$ & $\underline{\underline{55}}$ & $\underline{100.0 \%}$ \\
\hline \multirow[t]{3}{*}{ Implemented ERP } & Foreign vendor & 39 & $70.9 \%$ \\
\hline & Local vendor & 16 & $29.1 \%$ \\
\hline & $\underline{\underline{\text { Total }}}$ & $\underline{\underline{55}}$ & $\underline{100.0 \%}$ \\
\hline \multirow[t]{7}{*}{ ERP module mostly used } & All modules & 16 & $29.1 \%$ \\
\hline & Sales & 5 & $9 \%$ \\
\hline & Manufacture & 6 & $10.1 \%$ \\
\hline & Inventory & 11 & $20 \%$ \\
\hline & Accounting & 16 & $29.1 \%$ \\
\hline & Treasury & 1 & $1.8 \%$ \\
\hline & $\underline{\underline{\text { Total }}}$ & $\underline{\underline{55}}$ & $\underline{100 \%}$ \\
\hline \multirow[t]{3}{*}{ ERP implementation time } & Between 1 and 3 years & 14 & $25.4 \%$ \\
\hline & More than 3 years & 41 & $74.6 \%$ \\
\hline & $\underline{\underline{\text { Total }}}$ & $\underline{\underline{55}}$ & $\underline{100 \%}$ \\
\hline
\end{tabular}

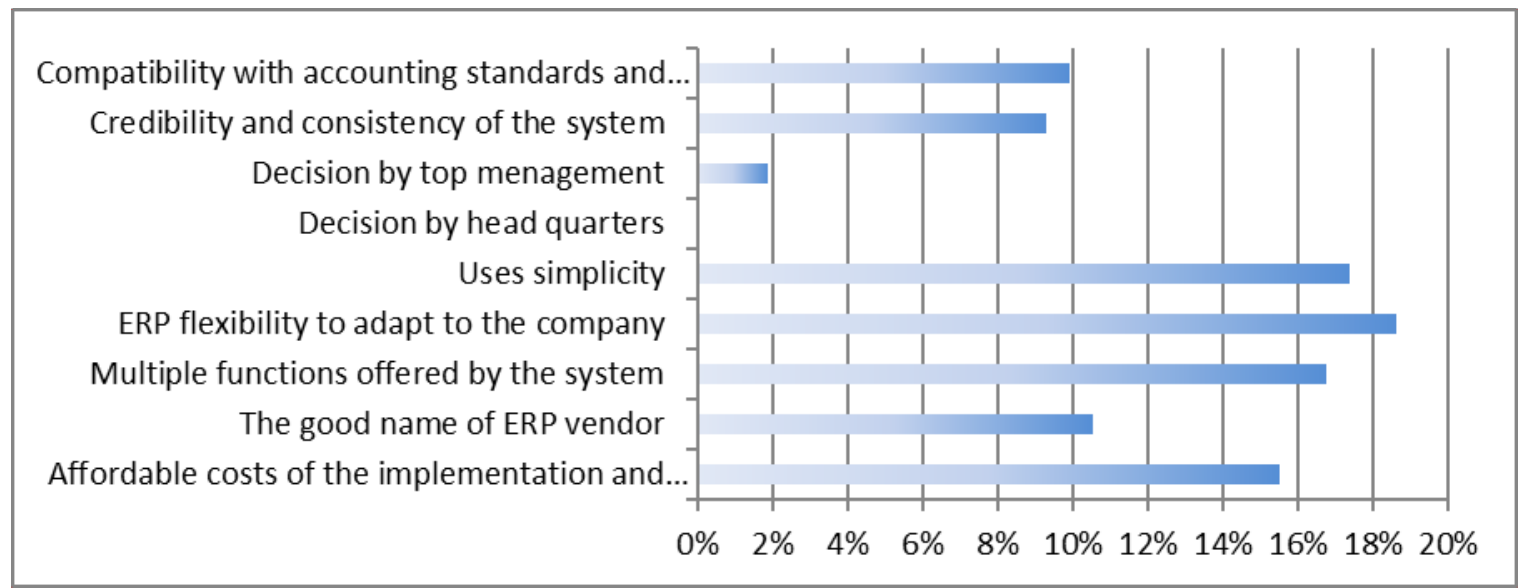

Fig.1: Factors that influence the selection of an Enterprise Resource Planning solution. 
As most of the participants in the study report a successful project, we consider this to be an indicator of their satisfaction with the ERP systems they are using.

The other questions of the survey focus on the research questions and are designed in Likert Scale type - respondents may chose from 1 (no impact at all) to 5 (most influential). Each question focuses on a variable which is presumed to have impact on the overall performance of ERP in an entity. We include 20 variables (as shown in table 2) that were selected during the literature review phase of the study. These variables are aggregated in three underlying factors by using a statistical software (SPSS). The graphical explanation of the total variance from three factors is presented in Scree Plot map, as it is shown below:

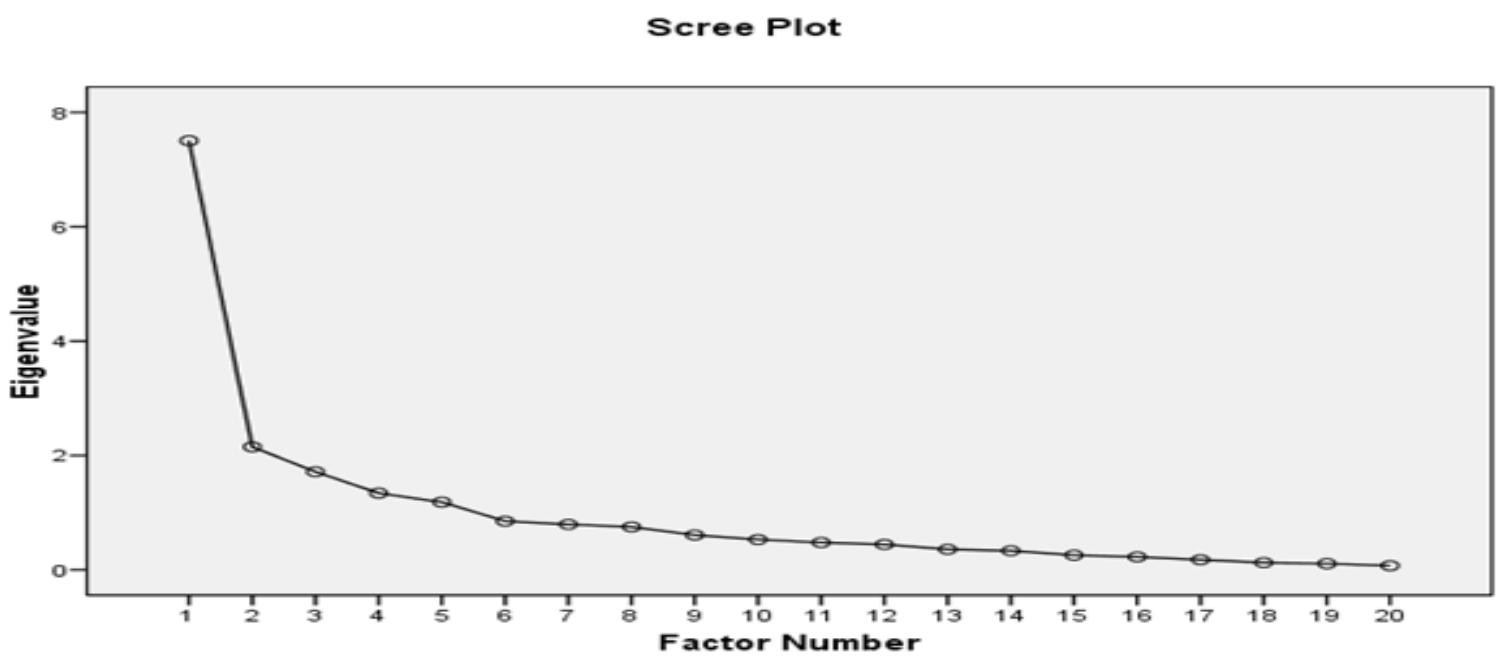

Fig.2: Scree Plot map of factorial analysis

As we see the plot line on figure 2, it almost flattens after the third factor, thus we include in our model of the total variance. Table 2 below represents a summarization of each of the three factors with their respective variables.

only the first three factors because they explain most

Table 2. Rotated factors matrix Extraction Method: Principal Axis Factoring. Rotation Method: Varimax with Kaiser Normalization

\section{Variables}

The accuracy of the information

User's satisfaction with ERP

The improvement of the employee's productivity

Security of ERP data

System's adaptability to business changes

The usefulness and timeliness of reports

The reliance on ERP for daily decision making

ERP impact in improving the inventory management

Improvement of communications among departmental units

Increase compliance with existing rules and regulations

Total cost reduction

Improvement of business processes flow

Availability of ERP providers in case of problems

Trainings offered by the vendor as part of the ERP project implementation

Contract with ERP consultants included in negotiations with ERP providers

System influence in business client relations improvements

The impact of ERP on sales growth

The impact of ERP on time delivery of customer orders

The impact of ERP on improving the decision-making process

The impact of ERP on improving the quality of financial reporting

\section{Factor 1 Factor 2 Factor 3 \\ 0.68 \\ 0.76 \\ 0.48 \\ 0.76 \\ 0.54 \\ 0.6 \\ 0.54}

0.34

0.90

0.51

0.53

0.49 
The goal of the Exploratory Factor Analysis is to group many variables into few distinctive factors variables that express different aspects of the same factor, and to highlight those variables with the highest variance (those variables that explain better the factors). Table 2 shows how the variables in our study are weighted for each factor and it also shows the correlation between variables and factors. (The possible values for the correlations range from -1 to 1. Correlations less than 0.3 are eliminated, so that the output could be easily readable).

We have identified the following three factors that have the biggest impact on the successful implementation of an ERP.

User satisfaction and overall quality of the ERP package - The user satisfaction is expressed through variables that measure the overall quality of the ERP package as perceived by its end users such as the accuracy of the information provided by the ERP, security of data, systems' adaptability to changes. This factor as shown in the scree plot (figure 2), seems to have the highest impact in our factorial model.

Cost Benefit profile of the ERP system - As the implementation of an ERP is a costly transaction, it is expected to increase effectiveness and improve communication as well as to reduce the overall costs by minimizing the manual work and reducing response time to organizational and legal requirements.

The vendor support - This last factor is represented by variables that reflect features of the ERP vendor such as the availability of the provider of ERP in case of problems, the ERP contract specifics and the ERP consultant readiness, and the trainings offered as part of the contract. As a considerable part of the contract is executed either by the vendor of the ERP or its implementing consultant, this factor is extremely important in determining the success of an ERP.

After we identify the factors that influence the level of success of the ERP project, we try to highlight in what extent each of these factors influences the firms of the sample according to their size. The level of influence was categorized in two discrete degrees: "low" when the rating given by the respondents was either 1 or 2 ; and "high" when the rating by the respondents was 3,4 or 5 . Table 3 shows the results of this categorization.

Table 3. The level of influence of each of the factors

\begin{tabular}{|c|c|c|c|c|c|c|c|c|c|c|}
\hline \multirow{2}{*}{\multicolumn{2}{|c|}{$\begin{array}{l}\text { Level of influence of } \\
\text { each factor }\end{array}$}} & \multicolumn{3}{|c|}{ Medium Firms } & \multicolumn{3}{|c|}{ Large Companies } & \multicolumn{3}{|c|}{ Total } \\
\hline & & \multirow{2}{*}{$\begin{array}{c}\begin{array}{c}\text { Foreign } \\
\text { ERP }\end{array} \\
\text { No }\end{array}$} & \multirow{2}{*}{$\begin{array}{c}\text { Albanian } \\
\text { ERP } \\
\text { No }\end{array}$} & \multirow{2}{*}{$\begin{array}{l}\text { Total } \\
\text { in } \%\end{array}$} & \multirow{2}{*}{$\begin{array}{c}\text { Foreig } \\
\text { n ERP } \\
\text { No }\end{array}$} & \multirow{2}{*}{$\begin{array}{l}\text { Albanian } \\
\text { ERP } \\
\text { No }\end{array}$} & \multirow{2}{*}{$\begin{array}{l}\text { Total } \\
\text { in } \%\end{array}$} & Foreign & Albanian & \multirow{2}{*}{$\begin{array}{c}\text { Tota } \\
1 \text { in } \\
\%\end{array}$} \\
\hline & & & & & & & & No & No & \\
\hline \multirow{3}{*}{$\begin{array}{c}\text { User } \\
\text { satisfaction and } \\
\text { ERP quality }\end{array}$} & Low & 3 & 7 & 56 & 2 & 12 & 41 & 4 & 19 & 46 \\
\hline & High & 2 & 8 & 44 & 3 & 17 & 59 & 4 & 23 & 53 \\
\hline & Total & 5 & 15 & 100 & 5 & 29 & 100 & 8 & 42 & 100 \\
\hline \multirow{3}{*}{$\begin{array}{l}\text { Cost Benefit } \\
\text { relationship }\end{array}$} & Low & 2 & 7 & 50 & 2 & 13 & 44 & 3 & 20 & 46 \\
\hline & High & 3 & 6 & 50 & 3 & 16 & 56 & 5 & 22 & 53 \\
\hline & Total & 5 & 13 & 100 & 5 & 29 & 100 & 8 & 42 & 100 \\
\hline \multirow[t]{3}{*}{ Vendor support } & Low & 4 & 6 & 56 & 2 & 13 & 44 & 5 & 19 & 48 \\
\hline & High & 0 & 7 & 44 & 3 & 16 & 56 & 3 & 23 & 52 \\
\hline & Total & 4 & 13 & 100 & 5 & 29 & 100 & 8 & 42 & 100 \\
\hline
\end{tabular}

We notice that the first factor: the end-user satisfaction is more important for the big companies rather than for medium firms. Referring to the fact that this factor is represented by variables such as the user's satisfaction, the data security and of the labor productivity this is an expected result, as the big companies engage many more users in the ERP and manage a larger volume of data than the medium companies. 
The second factor: the relationship between cost and benefits from the ERP implementation seems to be equally ranked on an average level by the medium sized firms but seems to have a higher impact for the big companies. This is an expected finding as the bigger companies usually implement larger ERPs, that are more costly and manage a wider area of daily business activities. The last factor: the support from the vendor, seems to have a higher impact for the medium companies maybe since in case of problems, these companies lack the appropriate support from their internal IT staff, compared to the big companies that usually have a more comprehensive coverage of internal problems form trained internal staff. Also, medium companies may even lack adequate funds to subcontract consulting IT companies to deal with such unexpected issues.

\section{Main Findings and Conclusions}

Enterprises resource planning systems not only represent big projects of investing in IT solutions, but ways of reorganizing the overall organization of firms by business processes reengineering. Such initiatives though require careful consideration of their success and risk factors both prior and during the implementation phase, as the chances of failing to achieve the desired results are quite high.

Recently, ERPs have been implemented in many Albanian medium and big companies. The first results of such big projects need to be researched to assess their level of success or risk factors. The aim of this study is to research the success factors (if any) of the ERP implementation projects in medium and big companies in Albania. We employ an explorative factorial analysis, and we base our study in the internal evaluation of the companies that have implemented such projects. As prior literature results show that there is usually a time lag for the ERP projects to give verifiable results in the performance indicators, we chose to measure the ERP success based on the perceptions of people working with them.

We distributed about 200 questionnaires and received back 55 valid completed surveys. We included 20 variables in the questions of this survey and later analyzed the variables by aggregating them to identify three main factors that impact the success (or not) of an ERP. We found that the first factor, user satisfaction and overall quality of ERP package is measured through the quality, reliability and security of the information provided by the system. The second factor is the cost-benefit relation of the ERP system - as the implementation of an ERP is a costly transaction, it is expected to increase effectiveness and reduce costs such as time and labor costs, minimizing the manual work and impacting on improving time to respond the organizational and legal requirements. The third factor, the vendor support which is the support offered from the ERP providers after the initial implementation is critical to ensure a streamlined use of the ERP after its initial success.

The results contribute to the existing stream of research that try to identify the factors that impact the success rate of ERP projects and offer valuable insights for other companies that are more and more considering investing in such risky technological solutions. These businesses must keep as a priority, the identification of a reliable ERP (both provider and consultant) that would increase the quality of the information as well as the satisfaction of the end users. Keeping in mind that the sample used in this study included many businesses operating in Albania with foreign capital, we may generalize our findings, because these entities are branches or subsidiaries of foreign firms that usually operate in the whole Eastern European Region. These organizations should also carefully analyze the expected costs and benefits of the implementation of the ERP, and finally they should negotiate to have the continuous support of the ERP vendor or the ERP implementation consultant throughout all the process.

Despite the contributions mentioned above, this study does not come without its limitations. The sample of the study may be extended in the future to be more representative and maybe include firms from other countries in the region to be a comparative study. Improvements in methodology are also possible and required to be implemented so that more factors can be identified and recommended to firms that want to consider investing in ERP solutions in the future. Lastly, including smaller firms in the study may bring useful insights for the perspective of implementing ERPs for smaller firms, which seems to be a trend in the current globalization of business. 


\section{References:}

[1] Kaplan, R. S., Norton, D. P., (1992), The Balanced Scorecard - Measures That Drive Performance, Harvard Business Review.

[2] Wang, ETG, Chen, JHF (2003), The Influence of Governance Equilibrium on ERP Project Success, Decision Support Systems.

[3] Wang, R. Y., Lee, Y. W., Pipino, L. L. \& Strong, D. M., (1998), Manage Your Information as a Product, Sloan Management Review.

[4] Chenhall, R.H. (2003), Management control systems design within organizational context: findings from contingency-based research and directions for the future, Accounting, Organization and Society.

[5] Holsapple, C., Sena, M., (1999), Enterprise system for organizational decision support: A research agenda. In: Proceedings of AMCIS.

[6] K. Doroshkevych, O. Maslak, V. Voronovska, ?. Salata, Use of Markov Chains for Modeling Processes of Strategic Planning of Innovative Activity of the Enterprise, WSEAS Transactions on Environment and Development, ISSN / EISSN: 1790-5079 / 2224-3496, Volume 16, 2020, Art. \#44, pp. 440-447.

[7] Batova Marina, Baranova Irina, Baranov Vyacheslav, Mathematical Modeling in High Tech Enterprise Innovation and Production Component Enhancing Strategy, WSEAS Transactions on Environment and Development, ISSN / E-ISSN: 1790-5079 / 2224-3496, Volume 16, 2020, Art. \#14, pp. 141-148.

[8] Davenport, T. H. (1998). Putting the enterprise into the enterprise system. Harvard Business Review (July-August): 121-131.

[9] Slooten, K., Yap, L., (1999), Implementing ERP information systems using SAP. In: Proceedings of AMCIS.

[10] Kumar K. and van Hillegersberg, J. (2000), Enterprise resource planning experiences and evolution. Communications of the ACM. Management System, Harvard Business Review.

[11] Alshawi, M. Themistocleous \& R. Almadani. (2004), Integrating Diverse ERP Systems: A Case Study', The Journal of Enterprise Information Management.

[12] Shehab, M.W. Sharp, L. Supramaniam \& T.A. Spedding, (2004), Enterprise Resource planning: An integrative review.
[13] Nicolaou, A. I.; Bajor,, L. H., (2011). ERP Systems Implementation And Firm Performance. Review of Business Information $\begin{array}{llll}\text { Systems } & \text { (RBIS) }\end{array}$ 10.19030/rbis.v8i1.4504

[14] Chung, S., Snyder, C., (1999), ERP InitiationA historical perspective. In: Proceedings of AMCIS.

[15] Arik, A.G. (2006), A Balanced Scorecard Model for the performance measurement of enterprise resource planning implementation. Benchmarking Partners. Deloitte Consulting Study, (1998), ERP's second wave: maximizing the value of ERP-enabled processes. Business Review.

[16] Nicolaou, A. I. Dehning B. Stratopoulos T. C. (2002). Financial Analysis of Potential Benefits from ERP Systems Adoption. Journal of Business and Information Technology, Volume 2, Issue 1, 2002.

[17] Hunton, JE, Lippincott, B, Reck, JL (2003), Enterprise Resource Planning Systems: Comparing Firm Performance of Adopters and Nonadopters, In: International of Accounting Information Systems.

[18] Grabski SV, Leech SA, Lu B., (2000), Successful implementation of ERP systems: risks and complementary factors. In: Seventh AIS Research Symposium, Scottsdale, Arizona.

[19] Hunton, EJ, McEwen, RA, Wier, B (2002), The reaction of Financial Analysts to Enterprise Resource Planning (ERP) Implementation Plans, In: Journal of Information Systems.

[20] Grabski, S. and Leech, S. (2007). Complementary controls and ERP implementation success. International Journal of Accounting Information Systems.

[21] Wieder B. Booth P. Matolscy Z. P. Ossimitz M. L. "The impact of ERP systems on firm and business process performance (2006). Journal of Enterprise Information Management 19(1):1329; DOI: $10.1108 / 17410390610636850$

[22] Kamhawi E. M. Critical Factors for Implementation Success of ERP Systems: An Empirical Investigation from Bahrain. (2007), International Journal of Enterprise Information Systems, Volume 3, Issue 2.

[23] Kim J. Nicolau A. I. Vasarhelyi "The Impact of Enterprise Resource Planning (ERP) Systems on the Audit Report Lag. December 2013, Journal 
of Emerging Technologies in Accounting 10(1):63-88. DOI: $10.2308 /$ jeta-50712

[24] Morris J. J. Measuring the Impact of Enterprise Resource Planning (ERP) Systems On Shareholder Value. March 2011. Review of Business Information Systems (RBIS) 15(1). DOI: 10.19030/rbis.v15i1.3996

[25] Holland, C., Light, B., (1999), A critical success factors model for ERP implementation. IEEE Software

[26] Kumar V, Maheshwari B, Kumar U, 2003 “An investigation of critical management issues in ERP implementation: Empirical evidence from Canadian organizations" Technovation 23(10):793-807 DOI: $\quad 10.1016 / \mathrm{S} 0166-$ 4972(02)00015-9

[27] Al-Mashari, M. (2002), Enterprise Resource Planning (ERP) Systems: A Research Agenda, Industrial Management and Data Systems.

[28] Aljarrah M. The Impact of Enterprise Resource Planning System of Human Resources on the Employees' Performance Appraisal in Jordan DOI: 10.37394/232015.2021.17.35. WSEAS Transactions on Environment and Development, ISSN / E-ISSN: 1790-5079 / 2224-3496, Volume 17, 2021, Art. \#35, pp. 351-359

[29] Tian, F., \& Xu, S. (2015). How Do Enterprise Resource Planning Systems Affect Firm Risk? Post-Implementation Impact. MIS Quarterly, 39(1), 39-60. Retrieved June 9, 2021, from https://www.jstor.org/stable/26628340

[30] Lin, P. (2019). Design and Implementation of Financial Accounting Information Management System of Shipping Companies Based on ERP. Journal of Coastal Research, 470-474. Retrieved June 9, 2021, from https://www.jstor.org/stable/26853985

[31] Kerr, D., \& Houghton, L. (2014). The dark side of ERP implementations: Narratives of domination, confusion and disruptive ambiguity. Prometheus, 32(3), 281-295. doi:10.1080/08109028.2015.1017247

[32] Bloom, N., Garicano, L., Sadun, R., \& Van Reenen, J. (2014). The Distinct Effects of Information Technology and Communication Technology on Firm Organization. Management Science, 60(12), 2859-2885. Retrieved June 9, 2021, from http://www.jstor.org/stable/24550344

[33] Rajan, C \& Baral, R. (2015). Adoption of ERP system: An empirical study of factors influencing the usage of ERP and its impact on end user. IIMB Management Review, 09703896, 27, 105-117.

[34] Rietveld, T. \& Van Hout, R. (1993). Statistical Techniques for the Study of Language and Language Behaviour. Berlin - New York: Mouton de Gruyter.

Contribution of Individual Authors to the Creation of a Scientific Article (Ghostwriting Policy)

\section{Author Contributions:}

- Prof. Asoc. Dr. Rezarta Perri Shkurti conceptualized the idea of the research and was responsible for all the stages of research, analysis, main findings, and recommendations.

- Dr. Elfrida Manoku has contributed for the management of survey distribution, and the revision of the paper after the comments from the reviewers.

\section{Creative Commons Attribution License 4.0} (Attribution 4.0 International, CC BY 4.0)

This article is published under the terms of the Creative Commons Attribution License 4.0 https://creativecommons.org/licenses/by/4.0/deed.en_ $\underline{\mathrm{US}}$ 